\title{
What not to do: Choosing wisely in nursing care
}

\author{
Anne Maria Eskes, Wendy Chaboyer, Paul Nieuwenhoven, Hester Vermeulen
}

It is widely recognised that research evidence is not readily being translated into practice (Nilsen, 2015). While traditionally the focus of the evidence practice gap has been on trying to get new, evidence-based interventions into practice, there has been growing attention on stopping ineffective interventions. With this latter focus, the concept of 'low-value' care has emerged, with some evidence that $10-30 \%$ of all healthcare practices have little or no benefit (Brownlee et al., 2017; Morgan et al., 2015).

The concept of low-value care is defined as care that is unlikely to benefit the patient given the harms, costs available alternatives, or preferences of the patients (Verkerk et al., 2018a). There are three types of low value care (Verkerk et al., 2018a), namely ineffective care, inefficient care and unwanted care. Ineffective care is described as low-value from the medical perspective and encompasses both ineffective care or the harms of the care outweigh the benefits, for the majority of the population or well-defined subgroups. Inefficient care reflects effective care that is used inappropriately and results in low-value from the societal perspective. Lastly, unwanted care is of low-value from the patient's perspective. This depends on the preferences and values of each individual patient.

Overuse of low value care can be perpetuated by a number of factors. Some suggest that both provider and patient factors contribute to the use of low-value care (Morgan et al., 2015). For example, the belief that more care is better, discomfort with uncertainty, and lack of knowledge of harm from overuse (Morgan et al., 2015). Others assert that individual, interprofessional and contextual factors influence the use of low-value care (Harvey and Mclnnes, 2015). The role cognitive biases such as 'therapeutic illusion' (i.e. the belief that the treatment is beneficial) play in this area has been a topic of recent interest (Casarett, 2016; Scott et al., 2017), although research in this area is in its infancy.

The recognition that overuse of low value care is a problematic and costs billions of dollars (Berwick and Hackbarth, 2012) led to the international Choosing Wisely Campaign. In 2014, this campaign expanded to nursing care. Choosing Wisely aims to stimulate shared decision making between clinicians and patients, to avoid low value care, by listing evidence-based 'do not do' lists. Up to now, some lists of wise choices for nurses have been compiled in Australia, Canada, USA and a more extensive one in the Netherlands. However, listing 'do not do's' in nursing can be extremely challenging as research in nursing is often observational, which makes it difficult to infer strong causal conclusions about the effectiveness of nursing interventions (Richards et al., 2018). It often fits the so-called 'grey zone', which makes it difficult for nurses to choose the most appropriate nursing intervention and prevent the use of low value care. 
However, for some nursing interventions high-quality evidence is available (e.g. omitting routine hair removal to prevent surgical site infections; omitting the routine use of urinary catheters in patients with acute stroke and urinary incontinence; and omitting the use of dressings for wounds closed by primary intention (Osorio et al., 2019). These recommendations are incorporated in 'do not do' lists (Osorio et al., 2019). However, the question arises if the use and uptake of these lists in daily practice is more or less rapid than it is for 'do lists' included in clinical guidelines.

It is frequently stated that it takes an average of 17 years for research evidence to be implemented into clinical practice (Westfall et al., 2007). But what about de-implementation of low value care? It seems that implementation and de-implementation are not simply two sides of the same coin (van Bodegom-Vos et al., 2017). van Bodegom et al. (2017) found that leaders in implementation are not necessarily also leaders in de-implementation. The only common barrier or facilitator to both was the outcome expected. Thus, it seems wise to shift the discourse to a more fine-tuned, tailored, nuanced approach to abandon low-value care in daily practice. That is, focusing on specific attributes which emerge from a systematic determinant analysis, for example using the Synthesis Model for the Process of De-Adoption by Niven et al. (2015). This model, which provides an overall process for de-implementation is based on the Knowledge to Action Framework implementation framework. The de-adoption model emphasises stakeholder engagement to identify and prioritise low value care. Prioritising should be based on safety of the low-value practice (i.e., harmful practices eliminated first), potential health and cost impact of de-adoption, and availability of alternative practices. Subsequent steps in the model include measuring current use of the low-value practice, adapting knowledge to local context, assessing barriers and facilitators to de-implementation, selecting and tailoring de-implementation strategies, evaluating the de-implementation process and outcomes, and sustaining de-implementation (Niven et al., 2015). However, like its implementation counterpart, this model may not provide enough information on specifics steps in the deimplementation process. For that, other theories such as behaviour change theories may be needed. Patey et al. (2018) have reviewed the theories used, finding that only one theory (operant learning) has been applied in a way that distinguishes between implementation and de-implementation.

Importantly, a tailored approach may be required as telling people what not to do may not be received well and is often not effective. The reasons for this are many and varied. In addition to cognitive biases mentioned earlier, recent work reported that the term 'disinvestment', another commonly used term for de-implementation, had strong negative connotations as it was associated with 'taking away', 'cost cutting', 'top down interference' and implied a criticism of current practice (Harris et al., 2017). Clearly, understanding de-implementation is in its infancy.

Realising this, it seems to be the right time to start focusing some of our research efforts on deimplementation. For example, it would be useful to know what terminology is acceptable, and motivates nurses to de-implement the recommendations made in do not do lists. This is extremely important in nursing science, as low-value activities absorbs and waste valuable resources of nurses, both in time and money (Verkerk et al., 2018b). Today, nurses have so little time; if they expend energy and effort on low-value care, they cannot spend time on other activities, like essential nursing activities. Therefore, we need to make wise choices and take action, as our time is a limited commodity. 


\section{References}

Berwick, D.M., Hackbarth, A.D., 2012. Eliminating waste in US health care. JAMA 307 (14), 15131516. doi:10.1001/jama.2012.362.

Brownlee, S., Chalkidou, K., Doust, J., Elshaug, A.G., Glasziou, P., Heath, I., Nagpal, S., Saini, V., Srivastava, D., Chalmers, K., Korenstein, D., 2017. Evidence for overuse of medical services around the world. Lancet 390 (10090), 156-168. doi:10.1016/ s0140-6736(16)32585- 5.

Casarett, D., 2016. The science of choosing wisely-overcoming the therapeutic illusion. N. Engl. J. Med. 374 (13), 1203-1205. doi:10.1056/NEJMp1516803.

Harris, C., Allen, K., King, R., Ramsey, W., Kelly, C., Thiagarajan, M., 2017. Sustainability in health care by allocating resources effectively (SHARE) 2: identifying opportunities for disinvestment in a local healthcare setting. BMC Health Serv. Res. 17 (1), 328. doi:10.1186/s12913-017-2211- 6.

Harvey, G., McInnes, E., 2015. Disinvesting in ineffective and inappropriate practice: the neglected side of evidence-based health care? Worldviews Evid. Based Nurs. 12 (6), 309-312. doi:10.1111/wvn.12137.

Morgan, D.J., Brownlee, S., Leppin, A.L., Kressin, N., Dhruva, S.S., Levin, L., Lan- don, B.E., Zezza, M.A., Schmidt, H., Saini, V., Elshaug, A.G., 2015. Setting a research agenda for medical overuse. BMJ 351, h4534. doi:10.1136/bmj.h4534.

Nilsen, P., 2015. Making sense of implementation theories, models and frameworks. Implement Sci. 10, 53. doi:10.1186/s13012-015-0242-0.

Niven, D.J., Mrklas, K.J., Holodinsky, J.K., Straus, S.E., Hemmelgarn, B.R., Jeffs, L.P., Stelfox, H.T., 2015. Towards understanding the de-adoption of low-value clinical practices: a scoping review. BMC Med. 13, 255. doi:10.1186/s12916-015-0488-z.

Osorio, D., Zuriguel-Perez, E., Romea-Lecumberri, S., Tinena-Amoros, M., Martinez- Munoz, M., Barba-Flores, A., 2019. Selecting and quantifying low-value nursing care in clinical practice: a questionnaire survey. J. Clin. Nurs. doi:10.1111/jocn.14989.

Patey, A.M., Hurt, C.S., Grimshaw, J.M., Francis, J.J., 2018. Changing behaviour 'more or less'-do theories of behaviour inform strategies for implementation and de- implementation? A critical interpretive synthesis. Implement Sci. 13 (1), 134. doi:10.1186/s13012-018- 0826- 6.

Richards, D.A., Hanssen, T.A., Borglin, G., 2018. The second triennial systematic literature review of european nursing research: impact on patient outcomes and implications for evidence-based practice. Worldviews Evid. Based Nurs. 15 (5), 333-343. doi:10.1111/wvn.12320.

Scott, I.A., Soon, J., Elshaug, A.G., Lindner, R., 2017. Countering cognitive biases in minimising low value care. Med. J. Aust. 206 (9), 407-411.

van Bodegom-Vos, L., Davidoff, F., Marang-van de Mheen, P.J., 2017. Implementation and deimplementation: two sides of the same coin? BMJ Qual. Saf. 26 (6), 495- 501. doi:10.1136/bmjqs2016-005473. 
Verkerk, E.W., Huisman-de Waal, G., Vermeulen, H., Westert, G.P., Kool, R.B., van Dulmen, S.A., 2018a. Low-value care in nursing: a systematic assessment of clinical practice guidelines. Int. J. Nurs. Stud. 87, 34-39. doi:10.1016/j.ijnurstu.2018. 07.002.

Verkerk, E.W., Tanke, M.A.C., Kool, R.B., van Dulmen, S.A., Westert, G.P., 2018b. Limit, lean or listen? A typology of low-value care that gives direction in deimplementation. Int. J. Qual. Health Care 30 (9), 736-739. doi:10.1093/intqho/ mzy100.

Westfall, J.M., Mold, J., Fagnan, L., 2007. Practice-based research-“Blue Highways" on the NIH roadmap. JAMA 297 (4), 403-406. doi:10.1001/jama.297.4.403. 